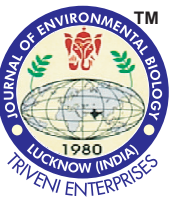

DOI : http://doi.org/10.22438/jeb/39/5/MRN-639

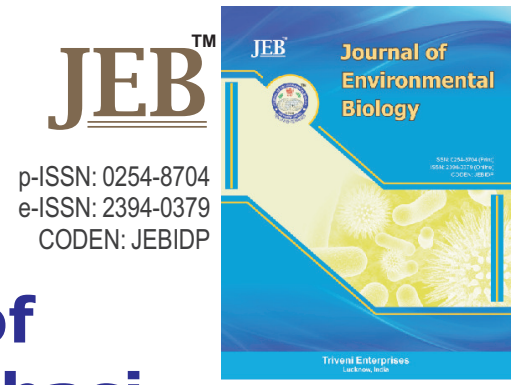

\title{
Farm level adaptation practices of potato growing farmers in East Khasi Hills district of Meghalaya, India
}

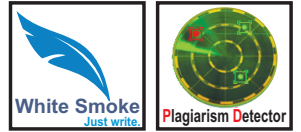

\section{Authors Info}

P. Kharumnuid ${ }^{1 *}$, I.S. Rao ${ }^{2}$, V. Sudharani $i^{2}$ and S. Kumar

'Division of Social Sciences, Central Potato Research Institute, Shimla-171 001, India

${ }^{2}$ Division of Agricultural Extension, Acharya N.G. Ranga Agricultural University, Hyderabad-500 030, India

${ }^{3}$ Division of Crop Improvement, Central Potato Research Station, Patna-801 506, India

*Corresponding Author Email : pynbiang.agri@gmail.com

Key words

Adaptation practices

Climate change

Ex-post facto

Farmer

Potato cultivation

Publication Info

Paper received : 02.05.2017

Revised received: 06.11.2017

Accepted: 05.12.2017

\begin{abstract}
Aim: This paper attempted to analyse the adaptation practices of potato farmers against the adverse effects of climate change in Meghalaya state of North East India, their level of adaptation and also the constraints to adoption of adaptation practices.
\end{abstract}

Methodology: The ex-post facto research design was selected for the study. The study was conducted in East Khasi Hills district of Meghalaya by interviewing 120 potato growers using interview schedule. The level of adaptation of each farmer to climate change was analyzed based on the total score of adaptation of each respondent farmer. The rank of each adaptation practice adopted by respondent farmers was analyzed using Weighted Mean Score. The constraints faced by potato growers to adoption of adaptation practices was identified by asking the respondents and simultaneously recording their responses.

Results: The findings revealed that there were twelve major adaptation practices followed by majority of potato growers. It also revealed that majority of the respondents had medium level of adaptation to climate change. The major constraints in adoption of adaptation practices were lack of quality seeds, price fluctuation in the market, low technical knowledge about improved potato cultivation, lack of efficient transport and marketing facilities, non-availability of production inputs and lack of information about weather and climate.

Interpretation: The study recommended that the farm level adaptation practices followed by famers need to be properly identified, documented, refined and validated before disseminating and integrating them into packages of practices for adaptation to climate change. Furthermore, these practices and adaptation constraints faced by farmers should be taken into account while developing future climate change strategies.
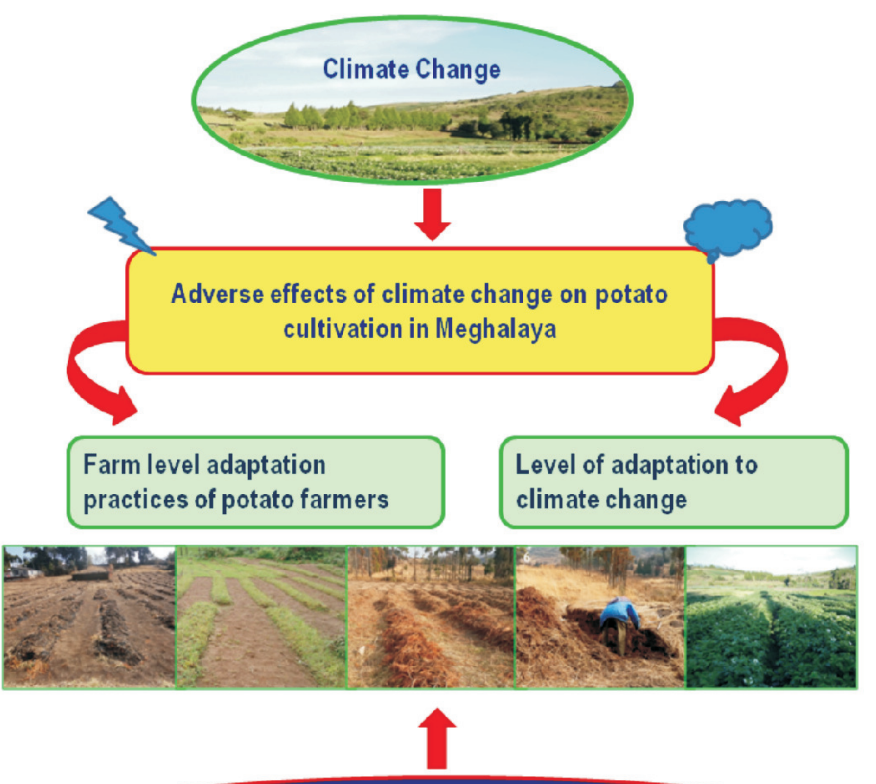

Adverse effects of climate change on potato cultivation in Meghalaya

Constraints to adoption of adaptation practices 


\section{Introduction}

Climate change is one of the greatest environmental challenges that pose a huge threat to the livelihood and development of billions of people all around the world. Even though it is a global phenomenon, it has differential impact on different parts of the globe (Komba and Muchapondwa, 2012) depending on the regional vulnerability and adaptation capabilities of the people in a particular region. Thus, climate change issue has been one of the major development agenda all over the world. The low-latitude tropical countries in South Asia and Africa are worst affected because of their poverty and high dependence on agriculture (NAAS, 2013; Swain, 2014). Like many other South Asian Countries, India is also one of the world's most vulnerable countries to climate change, because of its tropical climate, rainfed agriculture, poverty, large number of marginal and small farmers and inadequate resources and technologies to adapt to climate change (INCAA, 2010; Rao et al., 2010). In North East India, the adverse impacts of climatic change are far more evident than in other parts of the country (Kumar, 2011). This will have significant adverse impact in the region as more than two-third of population depends on agriculture and its allied activities. However, despite being viewed as a region with high vulnerability, climate change and its impact on agriculture and environment in North East India is poorly studied.

Climate change threatens all sectors of life, especially agriculture, since it has close relationship with climatic parameters such as precipitation and temperature, sunshine, wind direction and speed (Kumar, 2011). Thus, it is important to find ways to decrease the pressing threats of climate change in order to avoid social-economical destabilization and food insecurity (Nikolaishvili et al., 2015). Researchers and administrators all over the world have given their best efforts to reduce the adverse effects of climate change. Even farmers, using their own knowledge and wisdom, tried very hard to cope with threatening climatic factors. In many cases, farmers developed their own traditional practices due to lack of adequate financial and technological resources (Sarkar and Padaria, 2011). They may have valuable lessons to offer about successful and unsuccessful adaptations which could be vital in developing future climate change adaptation strategies (Macchi, 2008). Thus, in order to develop proper, farmers-friendly, low cost and sustainable adaptation strategies, integration of local adaptation practices of farmers in scientific researches is highly needed. Against this backdrop, the focus of this study was to identify and analyze the farm level adaptation practices followed by farmers and various constraints faced by them in adoption of adaptation practices.

\section{Materials and Methods}

Research design and sampling procedure : The ex-post facto research design was selected for the study. The study was conducted in Meghalaya state of North East India. Meghalaya is known for having the highest rainfall in the world in certain areas. Potato is the second most important crop after rice and it is well integrated into the dietary habits of people of Meghalaya and in their cropping system (Dubey and Sah, 2009). Potato is cultivated extensively in East Khasi Hills covering about 11.3 thousand hectares (64.2\%) of the total area (17.6 thousand hectares) under potato cultivation and also produces approximately 1.04 lakh MT (66.2 \%) of the total production (1.57 lakh MT) during 2014-15 (Anonymous, 2015). A multi stage sampling was followed for the present study. Out of seven districts of Meghalaya, East Khasi Hills district was selected purposively for the study, as it has the largest area under potato cultivation and also is the highest producer of potatoes. Two blocks, namely, Mawkynrew block and Mylliem block were selected using simple random sampling technique. Then, from each block, two Gram Sevak circles were selected randomly making a total of four circles. Subsequently from each selected circle, three villages were selected randomly making a total of 12 villages. Finally, ten respondents from each village were selected randomly making a total of 120 respondents.

Collection and quantification of data : The study was based on data collected from primary sources (potato growers) using a pretested and pre-structured interview schedule. The data so generated were subjected to simple descriptive statistics like frequency, percentage, weighted mean, etc. The adaptation practices of farmers were identified based on extensive review of related literatures and consultation with experts in climate change adaptation studies. Furthermore, 30 potato farmers were interviewed during pre-testing in order to elicit the major adaptation practices followed by them in the study area. The level of adaptation of each farmer to climate change was analyzed based on the total score of adaptation of each respondent farmer. The total score of adaptation was obtained by summation of (i) total number of adaptation practices followed by each farmer and (ii) weighted total score of adoption of adaptation practices which was calculated based on three point continuum Likert-type scale, viz., full adoption (score=3), partial adoption (score=2) and nonadoption (score=1) respectively. Consequently, the level of adaptation of each respondent were categorized into three classes, namely, low adaptation, medium adaptation and high using class interval method.

Furthermore, the rank of each adaptation practice adopted by potato farmers was analyzed using Weighted Mean Score (WMS) as follows:

where,

$$
\text { WMS }=\frac{F_{3} W_{3}+F_{2} W_{2}+F_{1} W_{1}}{F_{3}+F_{2}+F_{1}}=\frac{\sum F_{i} W_{i}}{\sum F_{i}}
$$

$F$ is the frequency of farmers; $W$ is weight of each scale; $i$ $=3$ for full adoption; 2 for partial adoption and 1 for non adoption. 
For identifying the constraints faced by potato growers in adoption of adaptation practices, the respondents were asked to express the constraints faced by them and were recorded simultaneously. Interview schedule was categorized into four sub-categories, viz., production, socio-economic, technology and institutional related constraints.

\section{Results and Discussion}

Level of adaptation of potato farmers : The findings revealed that majority of the respondents $(42.50 \%)$ had medium adaptation to climate change, followed by high $(30.00 \%)$ and low $(27.50 \%)$ adaptation to climate change respectively. The reasons for partial and non-adoption of some of the adaptation practices could probably be due to lack of knowledge about adaptation practices, lack and unavailability of resources for adaptation, lack and/or high cost of production inputs and other constraints (Table 2). It might also be due to the fact that majority of farmers in Meghalaya were poor marginal and small farmers.

Farm level adaptation practices of potato growers : Table 1 indicate that there were twelve major adaptation practices adopted by potato growers in the study area. Majority of farmers adopted the adaptation practices, however, the level of adoption of adaptation practices varied among the respondents. All farmers fully adopted nur synlei method of land preparation for autumn crop, use of organic manure, planting pit method and earthing up (traditional way) and were ranked first (I) with a mean weightage score (WMS) of 3 . These were subsequently followed by nur bun method of land preparation (2.94), use of improved high yielding varieties (2.39), crop diversification (2.17), minimum use of chemicals (2.02), mixed crop-livestock farming (1.93), early planting (1.8), off-farm diversification (1.75) and terrace cultivation (1.37).

"Nur bun" and "Nur synlei" methods are land preparation methods for summer potato and autumn potato crops respectively. Nur bun method is a modified form of Shifting or "Jhum" cultivation (Dubey and Sah, 2009). "nur" and "bun" is a Khasi language (Khasi language is spoken by Khasi tribes of Meghalaya), meaning "a raised bed" and "burnt materials" respectively. Thus, nur bun is a raised bed (20-25 cm high, 1-1.25 $\mathrm{m}$ width, 2-7 m length with 50-70 $\mathrm{cm}$ gap between them) made up of burnt materials. It is generally followed in hard compacted virgin or fallow lands, particularly in land with dense shrubs and grasses cover which are difficult for cultivation. Farmers followed nur bun method as it was difficult to cultivate potato and other crops in hard compacted lands. The soil in this method becoming light, friable and porous as the ash of burnt materials is added to soil, thereby, making potato cultivation easy (Yadav and Srivastava, 2015). Farmers also believed that the amount of fertilizers to be applied and the incidence of weeds, soil inhabited insects and soil borne diseases were also reduced. However, in Nur Synlei method, the stubbles along with soils were uprooted using a local spade (Mohkhiew) in order to get sods. The sods were then placed in bed and kept in upright position in such a way that it formed a raised bed. The bed was then covered with grasses, fallen tree branches, leaves, etc . A mixture of fertilizers, FYM (mainly poultry manure) and bleaching powder was then sprinkled over grasses before finally covering them with soil to form a raised bed having similar dimensions as in nur bun. Cow dung was not applied in autumn as farmers believed that it would cause rotting of tubers during heavy rains (August-September). Farmers perceived that this method enhanced root penetration and retention of moisture during dry season (OctoberDecember).

The study also revealed that all respondents used well decomposed manure for potato cultivation. Oluwasusi and Tijani (2013) also reported that farmers used organic manure/FYM for adaptation to climate change. Cow dung was used by majority of farmers for summer potato crops. Generally, farmers mixed cow dung with other organic materials like grasses, fallen leaves, small branches of trees, etc. and left them for decomposition. They perceived that apart from supplying nutrients to soil, oraganic manure also enhanced the water holding capacity leading to good germination and production. Farmers also believed that the use of organic manure reduced the cost of cultivation as they could be obtained from their farms. A large majority (78.33\%) of farmers adopted improved varieties like Kufri Jyoti, Kufri Megha, Kufri Girdhari and Kufri Giriraj that were high yielding and resistant to pest and diseases. Late blight of potato is the most devastating diseases in North Eastern Regions causing heavy loss in tuber yield (Dubey and Sah, 2009). Farmers reported that these varieties had considerably reduced the loss of tuber yield due to late blight and other diseases, leading to increase in production. Several researchers (Nhemachena and Hassan, 2007; Deressa et al., 2009; Uddin et al., 2014; Abid et al., 2015; Ndamani and Watanabe, 2015) also reported that one of the common adaptation methods in agriculture was use of improved crop varieties.

A traditional method of planting known as planting pit method was followed by all respondents. In this method, shallow pits of about 15-20 centimeters depth were dug on raised beds using mohkhiew, a local spade. The row to row spacing was kept at $30-40 \mathrm{~cm}$ and plant to plant at $15-20 \mathrm{~cm}$. Potato seed tubers were properly placed in dug pits and well decomposed manure and mixture of fertilizers was applied above the seed tubers before covering the pits finally with soil. Farmers perceived that the pit method of potato planting prevented drying of tubers and also enhanced germination even during dry season when there was no or less rainfall. The earthing up operation was followed by all farmers in their own traditional way. Earthing up is normally done when the crops attained a height of about $15-20 \mathrm{~cm}$. In this method, the soils between two beds were sliced and crushed properly with mohkhiew and spread over them, leaving the space 
Table 1 : Ranking of adaptation practices according to respondents' level of adoption of adaptation practices ( $N=120)$

\begin{tabular}{|c|c|c|c|c|c|}
\hline \multirow[t]{2}{*}{ Adaptation practices } & \multicolumn{3}{|c|}{ Level of adoption } & \multirow[t]{2}{*}{ WMS } & \multirow[t]{2}{*}{ Rank } \\
\hline & $\begin{array}{l}\mathrm{FA} \\
\mathrm{F}_{3}\end{array}$ & $\begin{array}{l}\mathrm{PA} \\
\mathrm{F}_{2}\end{array}$ & $\begin{array}{l}\mathrm{NA} \\
\mathrm{F}_{1}\end{array}$ & & \\
\hline Nur bun method of land preparation & $113(94.2)$ & $7(5.8)$ & $0(0)$ & 2.94 & $\|$ \\
\hline Nur synleimethod of land preparation & $120(100)$ & $0(0)$ & $0(0)$ & 3.00 & I \\
\hline Use of organic manure & $120(100)$ & $0(0)$ & $0(0)$ & 3.00 & I \\
\hline Use of improved varieties & $73(60.8)$ & $21(17.5)$ & $26(21.7)$ & 2.39 & III \\
\hline Planting pit method & $120(100)$ & $0(0)$ & $0(0)$ & 3.00 & I \\
\hline Earthing up (traditional way) & $120(100)$ & $0(0)$ & $0(0)$ & 3.00 & I \\
\hline Crop diversification & $52(43.4)$ & $37(30.8)$ & $31(25.8)$ & 2.17 & IV \\
\hline Minimum use of chemical fertilizers & $47(39.2)$ & $29(24.2)$ & $44(36.6)$ & 2.02 & V \\
\hline Mixed crop-livestock farming & $30(25)$ & $52(43.3)$ & $38(31.7)$ & 1.93 & $\mathrm{Vl}$ \\
\hline Early planting & $27(22.5)$ & $42(35)$ & $51(42.5)$ & 1.8 & VII \\
\hline Off-farm diversification & $22(18.3)$ & $46(38.3)$ & $52(43.4)$ & 1.75 & VIII \\
\hline Terrace cultivation & $11(9.2)$ & 23(19.2) & $86(71.6)$ & 1.37 & IX \\
\hline
\end{tabular}

Note: Figures in parentheses indicate the percentage of respondent farmers; Rating Scale: Full Adoption (FA) =3, Partial Adoption $(P A)=2$, Non Adoption $(\mathrm{NA})=1$

Table 2: Rank of constraints faced by farmers in adoption of adaptation practices to climate change in potato cultivation

\begin{tabular}{|c|c|c|c|c|}
\hline \multicolumn{3}{|c|}{ Constraints } & \multirow[t]{2}{*}{ Frequency } & \multirow[t]{2}{*}{ Rank } \\
\hline A. & Pro & tion related constraints & & \\
\hline & 1. & Lack of quality seeds of required varieties & $103(85.83)$ & I \\
\hline & 2. & Non-availability and/or high cost of production inputs & $93(77.50)$ & $\|$ \\
\hline & 3. & High incidence of disease & 91 (75.83) & III \\
\hline & 4. & Rainfed farming & $89(74.17)$ & IV \\
\hline \multirow[t]{5}{*}{ B. } & \multicolumn{4}{|c|}{ Socio-economic related constraints } \\
\hline & 1. & Price fluctuation in the market & $107(89.17)$ & I \\
\hline & 2. & Money requirement ahead of growing season for preparedness & $92(76.67)$ & II \\
\hline & 3. & Higher cost of cultivation using scientific methods & $86(71.67)$ & III \\
\hline & 4. & Preference for traditional practices of potato cultivation & $84(70.00)$ & IV \\
\hline \multirow[t]{5}{*}{ C. } & \multicolumn{4}{|c|}{ Technology related constraints } \\
\hline & 1. & Low technical knowledge of improved potato cultivation & $89(74.17)$ & I \\
\hline & 2. & Lack of information about weather and climate & $84(70.00)$ & $\|$ \\
\hline & 3. & Lack of proper knowledge on plant protection & $79(65.83)$ & III \\
\hline & 4. & Lack of information concerning adaptation options & $72(60.00)$ & IV \\
\hline \multirow[t]{6}{*}{ D. } & \multicolumn{4}{|c|}{ Institutional related constraints } \\
\hline & 1. & Lack of efficient transport facility in the village & $108(90.00)$ & I \\
\hline & 2. & Lack of efficient marketing facility & $106(88.33)$ & $\|$ \\
\hline & 3. & No weather related insurance and crop insurance facilities & $97(80.83)$ & III \\
\hline & 4. & Non-availability of credit and subsidy facilities & $93(77.50)$ & IV \\
\hline & 5. & Lack of proper storage & $89(74.17)$ & V \\
\hline
\end{tabular}

Note: Figures in parentheses indicate the percentage of respondent farmers; Note: Total percentage is $>100$ due to the multiple response of the respondents

between them clean. Farmers perceived that cleaning the space between two beds allowed run-off water to flow freely, thereby preventing damage of crops and beds during heavy rainfall and also helped in reducing weed population.

It is well known among farmers that greater crop diversity and mixed farming considerably safeguard against farming risk, including climatic-related risk (FAO, 2011), majority (74.16\%) of the respondent farmers also cultivated other crops like cabbage, maize, cauliflower, radish, knolkhol, pea, pumpkin, carrot, cucumber, etc. in addition to potato. Farmers perceived that crop diversification helped them in getting extra income and fresh vegetables for family consumption. Adger et al. (2003) and Orindi and Eriksen (2005) indicated that crop diversification can act as insurance against climate variability as different crops are affected differently by climate events. About $63.34 \%$ of farmers 
minimised the use of inorganic chemicals by utilising easily available and low cost farm resources like animal manures, wood ashes, plant residues, grasses, fallen leaves, etc. The consumption of fertilizers in Meghalaya is $14.35 \mathrm{~kg} \mathrm{ha}^{-1}$ which is very low as compared to rest of the India all India average (128.34 $\mathrm{kg} \mathrm{ha}^{-1}$ ) (Anonymous, 2013). There are some villages in Meghalaya where crops are still grown with organic manures as the only source of plant nutrients (Yadav and Srivastava, 2015). By following these practices, farmers perceived that the cost of cultivation had been largely reduced and also helped in maintaining soil fertility and water holding capacity of soil.

Apart from crop cultivation, majority of farmers $(68.33 \%)$ were also engaged in rearing of livestocks like cattle, pigs and poultry. Leftover/discarded vegetables and fruits from farms were used by them for animal feeding. Farmers reported that the income obtained from livestock rearing helped them to buy production inputs which in turn strengthening their adaptation capabilities. Livestock manures were used as fertilizers by the farmers. Farmers perceived that the cost of production of crops and livestock were reduced as animal manures and wasted crop residues could be procured from their farms. Nhemachena and Hassan (2007) also reported that mixed farming systems helped farmers in coping the adverse effects of climate change.

Early planting of potato crops was practised by more than half $(57.5 \%)$ of the farmers so that they could escape from the severity of disease like late blight, brown rot, etc. Early planted crops were harvested early and as a result cultivation of other crops, especially cabbage and lowland rice, are possible. Majority $(54.67 \%)$ of the farmers diversified into off-farm activities in order to get the needed finance and resources for potato cultivation. Farmers opined that income gained from off-farm activities helped in purchasing of production inputs, thereby enhancing their adaptation potentials to cope with adverse effects of climate change. Similarly, Singh et al. (2012) also reported that farmers opted for income diversification as an adaptation strategy to reduce their exposure to risk due to crop loss with increased climatic variability. However, the study found that very less number of farmers $(28.33 \%)$ followed terrace farming. By following terrace farming, farmers perceived that soil erosion due to heavy rainfall would be less thereby reducing washing off of soil and crops. They believed that cultivating of potato crops in terrace was a good adaptation strategy, but poverty and shortage of land constrained them from adopting it.

Constraints to adoption of adaptation practices : Multiple constraints can considerably reduce the range of adaptation options available to farmers and therefore may hinder them from adaptation to climate change (Barnett and O'Neill, 2010). The constraints experienced by farmers were categorized into four sub-categories as shown in Table 2.

Production related constraints: In this category, lack of quality seeds was the major constraint suffered by 85.83 per cent of the respondents. Similarly, Nhemachena and Hassan (2007) and Ishaya and Abaje (2008) also indicated that lack of seed inputs was important constraint for most farmers. This was followed by non-availability and high cost of production inputs which was experienced by 77.50 per cent of the respondent. The third hindrance reported by 75.83 per cent of the respondents was high incidence of disease. Rainfed farming was the last constraints reported by 74.17 per cent of the respondents. These constraints hampered the adaptation capabilities of potato growers and made them more vulnerable to the adverse impacts of climate change.

Socio-economic related constraints: Price fluctuation in the market was considered as the main problem in this category by 89.17 per cent of the respondents. Less market price of the produce reduced farmers' income which in turn deterred them from purchasing the necessary farm inputs and technologies needed for adaptation to climate change. The second problem reported by 76.67 per cent of the farmers was their requirement of money ahead of season for preparedness. Higher cost of cultivation using scientific methods was reported by 71.67 per cent of the respondents. About 70 per cent of farmers believed that using their own traditional practices, cost of cultivation would be less and were easy to follow.

Technology related constraints: The major problem in this category as expressed by 74.17 per cent of farmers was due to low technical knowledge in potato cultivation. Lack of extension services provided by the government, NGOs and other agencies and high level of illiteracy in the state could be the reason of farmers' lack of technical knowledge. The second problem which was expressed by 70.00 per cent of the respondent was lack of information about weather and climate. This constraint was also reported by other researchers (Ishaya and Abaje, 2008; Deressa et al., 2009; Ogunleye, 2013; Satishkumar et al., 2013). Information about climate is very important for preparing for climate change and lack of such information would reduce the adaptive capacity of farmers. This was followed by lack of proper knowledge on plant protection (65.83\%) and lack of information concerning adaptation options $(60.00 \%)$.

Institutional related constraints: In this category, lack of efficient transport facility in the village was considered as the major constraint by 90.00 per cent of the respondents. This was followed by lack of efficient marketing facility at village level, which was expressed by 88.33 per cent of the respondents. Marketing and transportation facilities play a vital role in adaptation preparedness as farmers need to sell their produce on time so that they can purchase production inputs for the next cropping season. The third problem mentioned by 80.83 per cent of the farmers was the absence of weather related crop insurance facility. Non-availability of credit and subsidy facilities and lack of proper storage was the fourth and fifth problems faced by 77.50 per cent and 74.17 per cent of the respondents, respectively. 
The findings of this study revealed that potato growers in Meghlaya followed their own local adaptation practices in addition to some recommended potato cultivation practices. They perceived that these adaptation practices were very helpful in adaptation to climate change. However, not all local adaptation practices are beneficial and sustainable in nature. Therefore, they need to be properly identified, documented, refined and validated. The study also revealed that farmers' decisions to adopt the adaptation practices were constrained by several factors. Thus, in order to develop future climate change strategies which are cost-effective, farmers-friendly and sustainable in nature, policy makers and researchers should take, inter alia, farm level adaptation practices/strategies and constraints faced by farmers in adopting them into account.

\section{References}

Abid, M., J. Scheffran, U.A. Schneider and M. Ashfaq: Farmers' perceptions of and adaptation strategies to climate change and their determinants: The case of Punjab province. Earth Syst. Dynam., 6, 225-243 (2015).

Adger, W.N., S. Hug, K. Brown, D. Conway and M. Hume: Adaptation to climate change in developing world. Prog. Dev. Stud., 3, 179-195 (2003).

Anonymous: Indian Fertilizer Scenario. Department of Fertilizers, Ministry of Chemicals and Fertilizers, Government of India (2013).

Anonymous: In conversation with people of Meghalaya: Horticulture. Meghalaya Basin DevelopmentAuthority, India (2015).

Barnett, J. and S. O'Neill: Maladaptation: Glob. Environ. Chang., 20, 211$213(2010)$.

Deressa, T.T., R.M. Hassan, C. Ringler, T. Alemu and M. Yesuf: Determinants of farmers' choice of adaptation methods to climate change in the Nile Basin of Ethiopia. Glob. Environ. Chang., 19, 248-255(2009).

Dubey, S.K. and U. Sah: Indigenous nur bun method of potato cultivation in Meghalaya hills. Asian Agrihis., 13, 147-153 (2009).

FAO: Strengthening capacity for climate change adaptation in agriculture: Experience and lessons from Lesotho. Environment and Natural Resources Management Series 18, Sales and Marketing Group - Communication Division, FAO, Rome, Italy (2011).

INCCA: Climate Change and India: A 4x4 Assessment-A sectoral and regional analysis for 2030s. INCCA Report 2, Ministry of Environment and Forests, Government of India, New Delhi, India (2010).

Ishaya, S. and I.B. Abaje: Indigenous people's perception on climate change and adaptation strategies in Jema'a local government area of Kaduna State, Nigeria. J. Geogr. Reg. Plann., 1, 138-43 (2008).

Kumar, K.V.V. and K.B Umesh: Perceptions and adaptation of the farmers to climate change. Karna. J. Agri. Sci., 28, 822-827 (2015).

Komba, C. and E. Muchapondwa: Adaptation to climate change by smallholder farmers in Tanzania. ERSA Working Paper 299, National Treasury of South Africa, Cape Town, South Africa (2012).

Kumar, M.: Evidences, Projections and potential impacts of climate change on food production in Northeast India. Indian J. Hill Farming, 24, 1-10 (2011).

Macchi, M., G. Oviedo, S. Gotheil, K. Cross, A. Boedhihartono, C. Wolfangel and $\mathrm{H}$. Matthew: Indigeneous and traditional peoples and climate change. Issue Paper, IUCN, Gland, Switzerland (2008).

NAAS: Climate resilient agriculture in India. Policy Paper 65. National Academy of Agricultural Sciences, New Delhi, India (2013).

Ndamani, F. and T. Watanabe: Farmers' perceptions about adaptation practices to climate change and barriers to adaptation: A microlevel study in Ghana. Water, 7, 4593-4604 (2015).

Nhemachena, C. and R. Hassan: Micro-level analysis of farmers' adaptation to climate change in Southern Africa, IFPRI Discussion PaperNo. 00714. IFPRI, Washington DC (2007).

Nikolaishvili, D., V. Trapaidze, B. Kalandadze, T. Mamukashvili and M. Sharashenidze: Complex evaluation of climate change - an example from Georgia's landscapes. J. Environ. Biol., 36, 43-49 (2015).

Ogunleye, K.Y.: Farmers' perception of the effect of climate change on crop production in egbedore local government area of Osun state, Nigeria. Int. J. Sci. Res., 4, 832-835(2015).

Oluwasusi, J.O. and S.A. Tijani: Farmers adaptation strategies to the effect of climate variation on yam production: A case study in Ekiti State, Nigeria. Agrosearch, 13, 20-31 (2013).

Orindi, V.A. and S. Eriksen: Mainstreaming adaptation to climate change in the development process in Uganda. Ecopolicy Series 15. African Centre for Technology Studies, Nairobi, Kenya (2005).

Rao, A.V.M.S., P.S.B. Chowdary, N. Manikandan, G.G.S.N. Rao, V.U.M. Rao and Y. Ramakrishna: Temperature trends in different regions of India. J.Agrometeorol., 12, 187-190 (2010).

Satishkumar, N., P. Tevari and A. Singh: A Study on constraints faced by farmers in adapting to climate change in rainfed agriculture. $\mathrm{J}$. Hum. Ecol., 44, 23-28 (2013).

Sarkar, S. and R.N. Padaria: Understanding indigenous knowledge system in coastal ecosystem of West Bengal. J. Comm. Mobilis. Sus. Dev., 6, 19-24 (2011).

Singh, N.P., M.C.S. Bantilan, K. Byjesh and M.V.R. Murty: Adapting to climate change in agriculture: Building resiliency with an effective policy frame in SAT India. Policy Brief No. 18. ICRISAT, Patancheru, India (2012).

Swain, M.: Crop insurance for adaptation to climate change in India. Asia Research Centre Working Paper 61, The London School of Economics and Political Science, London, UK (2014).

Uddin, M.N., W. Bokelmann and J.S. Entsminger: Factors affecting farmers' adaptation strategies to environmental degradation and climate change effects: A farm level study in Bangladesh. Climate, 2, 223-241 (2014).

Yadav, S.K. and A.K. Srivastava: A review on agronomical aspects of potato production in North-Eastern region of India. Int. J. App. Pure Sci. Agri., 1, 26-34 (2015). 